\title{
Patterns and Prevalence of Alcohol Use among University of Utopia Students in South Africa
}

\author{
Posthumous: Prof Lily Cherian ${ }^{1}$ \\ School of Education, University of Limpopo, South Africa \\ Mr Mdumo Mboweni \\ School of Education, University of Limpopo, South Africa \\ hopi.mboweni@ul.ac.za \\ Layane Mabasa \\ School of Education, University of Limpopo, South Africa \\ thomas.mabasa@ul.ac.za \\ Thinavhudzulo Mafumo \\ School of Education, University of Limpopo, South Africa \\ thinavhudzulo.mafumo@ul.ac.za
}

Doi:10.5901/mjss.2014.v5n20p1573

Abstract

Substance use - alcohol in particular, is common amongst secondary school learners in the area surrounding the researched university in South Africa. This phenomenon has also been observed as occurring in the university under study (University of Utopia). The researchers became aware of alcohol use amongst students especially after events such as the 'Freshers' ball', Mr. and Mrs. University of Utopia functions, festivals and other events where first year students are welcomed at the university. We were thus motivated to undertake this study on the patterns and prevalence of alcohol use amongst second year university students. A descriptive study utilising a self-reporting questionnaire developed by the World Health Organization (WHO) was carried out. A total sample of 120 Education second year students (59 females and 61 males) was randomly selected. The questionnaire addressed the following issues: information on life experience, current and past use of substances like tobacco and alcohol as well as illicit drugs such as marijuana or cannabis (called dagga in South Africa), inhalants, heroin, amphetamines, sedatives, $d$-Lysergic Acid Diethylamide (LSD) and cocaine. The study found that the prevalence of the use of alcohol and other substances among university students was high and that males had a higher prevalence rate than females. The study concludes by indicating that recognising early symptoms of alcohol dependence may assist in the early identification and intervention for those at risk of heavier drinking in the future.

Keywords: Alcohol use, University of Utopia students, Prevalence

\section{Introduction}

The consumption of alcohol beverages in South Africa has a long established history. During the pre-colonial times, alcohol consumption was mainly the preserve of elders and senior members of society including traditional leaders, but was uncommon among youth and women of childbearing age (Adolescent) stage (Peltzer and Ramlagan, 2007).

Adolescence is a time of transition during which the body is undergoing many significant changes, including hormonal alterations and brain development. Furthermore, it is a period when young people begin associating more intensively with friends and associates extending beyond the circle of their childhood contacts. Today's generation of young people - the largest such group in South Africa - is approaching adulthood in a world vastly different from that encountered by previous generations, characterised by amongst others, factors such as globalisation, urbanisation, accelerated information communication technologies, migration, and economic challenges. These, seem to have

\footnotetext{
1 In memory of Professor Lily Cherian who unexpectedly passed away on August 6, 2013
} 
contributed towards different kinds of changes in life styles including alcohol as a form of relaxation and entertainment. This phenomenon seems to be prevalent amongst high school learners and students at institutions of higher learning. Fatusi and Hindin (2010) assert that the transition from adolescence to productive and healthy adults is, inter alia, shaped by societal context, including gender and the socialisation process. According to them, nearly all students in both developing and developed countries claim that they have used alcohol before the completion of high school or when they first enter university, with over a third reporting hazardous use at least once. Although many young people may drink less regularly than adults, they tend to engage in binge drinking during events such as "Freshers' ball" and festivals. Drinking to a point of intoxication is of concern because of the associations between alcohol consumption and road accidents, suicides, homicides and violence. Worldwide trends indicate that when a country experiences frequent general and drastic socio-economic or political change, this impacts on the sphere of high-risk behaviour especially among young people (Visser and Moleko, 1999). Hazardous bouts of alcohol use have also been related to increased risk of contracting Sexually Transmitted Infections (STIS) and Human Immunodeficiency Virus (HIV) infection, the likelihood of teenage pregnancy and poor academic performance (Madu and Matla, 2003). Further, at the University of Utopia, during big events like festivals it is almost a norm that students use alcohol. This can be seen by alcohol containers like bottles and cans strewn all over the campus. This is usually accompanied by some anti-social activities like group sexual activities, rape and cases of fighting and stabbings. Alcohol use also happens over weekends.

It is within this context that the researchers became interested in conducting a study on alcohol use on campus. The focus of the study was on the patterns and prevalence of alcohol use at the University of Utopia.

\section{Rationale for the Study}

There are many alcohol related incidences reported at the Safety and Control Centre of the University of Utopia. Studies have been conducted in and around the University of Utopia on substance use in general. They are studies by (Peltzer and Cherian 2000; Madu and Matla, 2003). However, there are not many studies conducted focusing on alcohol use only in and around the University of Utopia. It is against this background that this study was conducted at the University of Utopia focusing on the patterns and prevalence of alcohol use by students on campus. Alcohol use was selected to be the focus of the study because it is rife and it results in anti-social behaviour such as group sexual activities, rape and cases of fighting and stabbings. Further, as Nkonzo-Mtembu (1994) indicates, when people are frequently inebriated, their troubles are increased; this also applies to adolescents.

\section{Purpose of the Study}

Alcohol is undoubtedly the main substance of choice for most South Africans, especially the youth (Bauman and Phongsavan, 1999). Both commercial and home-brewed beverages are consumed fairly extensively in the rural areas of South Africa. The university under study, is one of the few located in a rural area, hence this study. The main purpose was to investigate patterns and prevalence of alcohol use amongst second year students of the University of Utopia. According to Parry, Myers, Morojele, Flisher, Bhana, Donson and Pluddemann (2004) most studies in South Africa are undertaken in the urban areas, for example, Cape Town and Durban. A study of this nature in a rural area will provide University authorities with information that may be helpful in developing intervention strategies in dealing with alcohol use on campus.

\section{Research Questions}

This study investigated the following research questions:

- What are the patterns of alcohol use amongst students at the University of Utopia?

- What is the prevalence of alcohol use at the University of Utopia?

\section{Theoretical Framework}

There are several theories that give reasons for alcohol use amongst adolescents. Amongst others, there are theories that emphasise substance-specific-cognitions, social learning processes, commitment to conventional values and attachment to families, and intrapersonal processes (Petraitis, Flay and Miller, 1995). For the purpose of this article social learning and developmental theoretical frameworks were adopted. The adoption of these theories was informed by the view as espoused in the social learning theory that some people emulate the behavior of significant others as they 
develop. This is in line with the developmental theory which indicates that when young people are in a new situation, they are in a state of flux and as a result they tend to look at whom they regard as a role model in what they do (Masten, Faden, Zucker and Spear, 2008). Social learning theory emphasises not only the place of reinforcement of behaviour but also the effects of cues on thought. Bandura (1986) stresses the phenomena of modelling: the imitation of the significant other's behaviour as well as that of vicarious experience, i.e. learning from others' successes or failures (Slavin, 2012). Social learning theory is based on recognition of the importance of observational learning and self-regulated learning. Bandura's observational learning theory is motivated by an expectation that correctly imitating the model will lead to reinforcement of the behaviour. People learn by seeing others reinforced or punished for engaging in certain behaviours (Bandura,1986; Zimmerman and Schunk, 2003). Children emulate the behaviours shown by their role models, the value of these models going beyond the specific abilities they possess. People adopt behaviours consciously and unconsciously daily through observing others. Almost every action by others has the potential of being modelled. There are several factors which play a role in social learning: attention, memory, motor skills, reinforcement, identification, the status of the model and nurturing model (Mwamwenda, 2004). Some behaviour elicits a sense of appeal to a person to engage in imitating another person's behaviour. This theory connects with the use of alcohol in the sense that most of the adolescents use alcohol as a result of imitating those whom they regard as their role models (Eklund, 2006).

\section{Review of Literature Related to the Study}

Alcohol use in South Africa is among the highest in the whole of Africa (Pengpid, Peltzer, van der Heever and Skaal, 2013). Its use is also rife among the adolescents and it is becoming an alarming public health problem (Setlalentoa, Pisa, Thekiso, Ryke and Du Loots 2010, Ghuman, Meyer-Weitz and Knight, 2012). This is becoming a major cause for concern because its intake is associated with anti-social behaviors like unsafe sex, dropping out of school and teenage pregnancy.

It also contributes to a wide range of other health and social problems in South Africa (Morojele, 1997). This phenomenon (alcohol use) is also becoming a problem at university campuses in South Africa. The problem was also noted by Kalideen (2011) who indicated that alcohol use is rife at the university campuses in South Africa. The students go to an extent of using bursary money to buy alcohol for entertainment. In some cases, drinking does not stop because it does not have a starting point. The situation notwithstanding, studies do not seem to focus much on the issue of student alcohol use on campuses. There are however, some few studies that have tried to look at the issue of alcohol use at South African universities. Some of the studies that have been conducted are studies by Young and de Klerk (2008), Young and Mayson (2010) and Pengpid et al. (2013).

Young and de Klerk (2008) focused on the patterns of alcohol usage in one of the Universities in an urban area in South Africa. They found that there was a high prevalence of harmful alcohol use among university students. Young and Mayson (2010) in the same university two years later found that alcohol consumption was very high amongst the students with males using more alcohol than females.

Other studies reviewed are those that have been conducted among high school learners. One of the studies is the study by Peltzer and Cherian (2000). They found that a prevalence of alcohol use was higher than the use of other substances in both urban and rural schools. They presented their results as follows: $34.9 \%$ for alcohol, $22.5 \%$ for tobacco, $11.0 \%$ for cannabis, $6.7 \%$ for cocaine, $6.7 \%$ for inhalants, $8.6 \%$ for amphetamines and $7.2 \%$ for sedatives or tranquillisers in urban secondary pupils in one of the cities in the Limpopo Province (South Africa). In rural secondary school pupils, the results were $25.7 \%$ for alcohol, $8.4 \%$ for tobacco, $6.8 \%$ for cannabis, $4.7 \%$ for cocaine, $4.2 \%$ for inhalants, $3.1 \%$ for amphetamines and $2.6 \%$ for sedatives or tranquillisers. It is apparent that alcohol is more consumed than all other substances.

A study by Madu and Matla (2003) in the Polokwane area of Limpopo Province of South Africa looked at the prevalence of alcohol use by gender. The study found that the prevalence of alcohol use had risen where $49.9 \%$ males used alcohol and 32.1\% females used alcohol. Another study by Flisher, Parry, Evans, Muller and Lombard (2003) reported prevalence rates of $21.9 \%$ for cigarette smoking, $34.7 \%$ for alcohol drinking among pupils in Cape Town.

Onya, Tessera and flisher (2012) also conducted a study on adolescent alcohol use in rural South African high schools. The study focused on the prevalence and correlates of alcohol use among adolescents in rural high schools in South Africa. The study found amongst others that personal attributes such as gender and age, psychological challenges and environmental domains like availability and social norms around alcohol use are correlated with high school students' alcohol use.

In each of the above studies in South Africa, the general tendency is that alcohol use is associated more with males than with females, with use increasing with age. There is also a close relationship between alcohol drinking and 
smoking by students. Gender is found to be an important predictor and one of the main factors that account for alcohol use. Different studies have reported that males take alcohol more intensively than females (Peltzer, Cherian and Cherian 1999: Peltzer and Phaswana 1999; Spruijt and Jurijen, 1999; Madu and Matla 2003). Gender difference in usage; however, appears to be less distinct for other drugs such as heroin and cocaine.

Even though some of the studies reviewed did focus on the use of alcohol by students on campus, most of them focused on the campuses in urban areas. This article tries to explore the phenomenon of alcohol use in a rural area focusing on the prevalence and patterns.

While speaking to the respondents in the study, the researchers were informed that they drink alcohol for a variety of reasons: for taste, experimentation, for pleasure and relaxation, out of curiosity, for gaining insight, to conform, to help "feel comfortable", "because everyone does it", for dealing with loneliness, friends use it, to model drinking parents, to forget problems or trouble.

\section{Research Method and Design}

By means of a questionnaire, the study used a quantitative approach to collect data from students. A descriptive survey design (McMillan and Schumacher, 2010) was used. The design was decided upon since we wanted to study the current patterns and prevalence of alcohol use amongst sophomores.

\subsection{Population and Sample}

182 second year Education Studies students from the given university formed the population of the study. A sample of 120 students (59 females and 61 males) was randomly selected. The mean ages for males was 18.26 (SD=1.625); and for females was $18.84(S D=1.366)$.

\subsection{Data Collection Instrument}

Data pertaining to prevalence and frequency of alcohol use was obtained from a questionnaire developed by WHO (Smart, 1980). The questionnaire is meant to obtain data on substance use in general, but for the purpose of this study the focus was on alcohol use. A series of items is given to a group of willing respondents. In this instance the researchers relied on self-report data. The reliability co-efficient of the questionnaire was determined to be .87 and the content validity was confirmed by colleagues in the field of Education, at the university. Respondents' demographic variables were determined by use of a questionnaire which covered personal characteristics such as age and gender. Items related to substance use were approached in the following manner: For tobacco, students were asked: "Have you ever smoked, chewed or sniffed any tobacco product (such as cigarettes, cigars, pipe, chewing tobacco)?" Response options were "Yes" or "No". For alcohol, students were asked, "Have you ever drunk any alcohol (including beer, wine or spirit)?" "Yes" or "No" were response options. They were further asked, "If your answer was "Yes", please estimate the number of times you drank alcohol during the past 30 days". The same response options for the preceding questions were used for the questions that followed. Clarification of terms and the concepts used in the questionnaire were provided.

Questionnaires were completed in a lecture hall during the researchers' normal one-hour lecture periods; to which permission was granted by the University authorities. On average students took 30 to 40 minutes to complete the questionnaire.

\section{Ethical Considerations}

Approval for the study was obtained from the University of Utopia Research Ethics Committee. Respondents were informed of the aims, purpose and potential risks of the study as well as the emotional and psychological discomfort it might entail. The respondents were also informed of their rights to abstain from participation or withdraw consent to participate at any time without reprisal. They were told not to write their names in order to conceal their identity.

\section{Data Analysis}

We used the WHO instrument for the collection of general data on substance use as already indicated. Substance use was partly investigated albeit not the main aim of this study. Researchers had observed that individuals, who engaged in substance use, also drank alcohol. Consequently, the following statistical data analyses were employed; T-test to 
compare differences in substance use between males and females and descriptive statistics such as mean and standard deviation.

\section{Results}

\subsection{Prevalence of substance/drug use in general}

Table 1 shows the prevalence of substance use and illustrates that the prevalence of alcohol use among the respondents was $87 \%$ ( $82 \%$ for males and $63 \%$ for females); indicating that substance use is more associated with males than females. It should however, be indicated that the sample group had more males than females. The results also indicate that alcohol (87\%), tobacco (47\%), dagga (38\%), and inhalants (19\%) in descending order, were the most prevalent substances used.

Table 1: Prevalence rates of substance/drug use by gender

\begin{tabular}{|c|c|c|c|c|c|c|}
\hline \multirow{2}{*}{ Substance } & \multirow{2}{*}{ Response } & \multicolumn{2}{|r|}{ Male } & \multicolumn{2}{|r|}{ Female } & \multirow{2}{*}{ Total } \\
\hline & & \begin{tabular}{|l|} 
Number \\
\end{tabular} & \begin{tabular}{|l|} 
Percentage of category \\
\end{tabular} & Number & Percentage of category & \\
\hline \multirow{3}{*}{ Alcohol } & Yes & 50 & 82 & 37 & 63 & 87 \\
\hline & No & 11 & 18 & 22 & 37 & 33 \\
\hline & Total & 61 & 100 & 59 & 100 & 120 \\
\hline \multirow{3}{*}{ Tobacco } & Yes & 41 & 67 & 6 & 10 & 47 \\
\hline & No & 20 & 33 & 53 & 90 & 73 \\
\hline & Total & 61 & 100 & 59 & 100 & 120 \\
\hline \multirow{3}{*}{ Dagga } & Yes & 34 & 56 & 4 & 7 & 38 \\
\hline & No & 27 & 44 & 55 & 93 & 82 \\
\hline & Total & 61 & 100 & 59 & 100 & 120 \\
\hline \multirow{3}{*}{ Inhalants } & Yes & 15 & 25 & 4 & 7 & 19 \\
\hline & No & 46 & 75 & 55 & 93 & 101 \\
\hline & Total & 61 & 100 & 59 & 100 & 120 \\
\hline \multirow{3}{*}{ Amphetamines/Stimulants } & Yes & 8 & 13 & 11 & 13 & 19 \\
\hline & No & 53 & 87 & 48 & 87 & 101 \\
\hline & Total & 61 & 100 & 59 & 100 & 120 \\
\hline \multirow{3}{*}{ Tranquillisers/Sedatives } & Yes & 7 & 11 & 1 & 2 & 8 \\
\hline & No & 54 & 89 & 58 & 98 & 112 \\
\hline & Total & 61 & 100 & 59 & 100 & 120 \\
\hline \multirow{3}{*}{ Cocaine } & Yes & 7 & 11 & 3 & 5 & 10 \\
\hline & No & 54 & 89 & 56 & 95 & 110 \\
\hline & Total & 61 & 100 & 59 & 100 & 120 \\
\hline
\end{tabular}

\subsection{Differences in substance use between males and females}

The mean for males was $4.76(S D=3.71)$ while that for females was $3.04(S D=1.77)$. There is a significant difference in the use of substances between male and females with $p=0.002$.

Figure 1 shows the gender difference in substance/drug use.

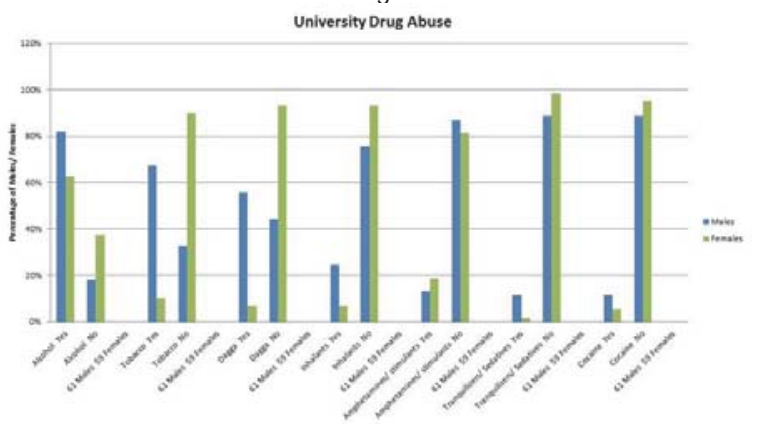

Figure 1: 


\subsection{Other substances}

Respondents were asked to indicate any other substances that they used; the following were reported: heroin, mandrax, phethidine, roches, morphine, methylated spirit, mebolec, bio-slim burn-down, bio-slim sugar free and fat blocker. The above-mentioned results indicate that new patterns and trends of substance in use among adolescents may be emerging, especially among females.

The study variously revealed the following reasons for alcohol use: during the festive season, to release tension, at parties, to experiment, headache, to imitate role models, feel sexy, it's cool, want to be a man, refresh one-self, medical purposes, forget problems, feel high, relaxation and getting energy.

\section{Discussion and Conclusion}

Substance use and alcohol in particular is a growing problem amongst youth at tertiary institutions. Results from this study show: a high prevalence of substance use among university students where alcohol is the most widely used substance at the University of Utopia. The results are in line with the findings by Young and de Klerk (2008) and Young and Mayson (2010) who found that there was a high level of alcohol use at Higher Education Institutions. Further, the study found that alcohol drinking behaviour is associated more with males than with females. This resonates with findings by Young and Mayson (2010) that alcohol consumption was very high amongst males than female at the Higher Education Institution that they had studied.

In South Africa, as in other countries, substance use is more prevalent among males than females; this global trend is confirmed by studies done in other countries (Zhang, Lu, Zhang, Song, Li and Kang, 2013; Atav and Spencer, 2002). Drinking to the point of intoxication is reported by some students in this study and is of concern due to the potential link between alcohol consumption and social ills. Recognising early symptoms of alcohol dependence may assist in the early identification and intervention for students at risk of heavier drinking in the future.

\section{Recommendations}

The findings show that there is a high level of alcohol use by the students at the University of Utopia. Due to the high level of alcohol consumption, there is a need for some intervention to deal with this phenomenon. Intervention programmes can be designed to alleviate the undesirable consumption of alcohol. Further, the University of Utopia should provide wide-ranging recreational environments that may keep the students engaged other than to be preoccupied with alcohol. The University of Utopia should develop a policy on alcohol use on campus. This may help to regulate and in the process reduce the level of alcohol abuse among the students on campus. These results, also suggest that there is a need to prevent early beginnings of alcohol intake among South African youth. This can be done by initiating on and off campus campaigns that encourage students to abstain from excessive alcohol escapades.

\section{Limitations}

The present small-scale study relied mainly on the self-report questionnaire, which is subject to intentional distortion. Its use though was based on McDonald (2008) that the use of self-report questionnaire is important in that the data is constructed by getting information directly from the respondents. The sample was rather homogenous in terms of age and research site. On hind sight, we could have sampled the same age cohort from other fields in different Faculties. For example, all the respondents were second year Education Studies students aged between 16 and 20 years, and the sample was very small in this regard. The results of the present study can therefore not be generalised to the entire student population. Hence, the above-mentioned limitations should be taken note of by future researchers.

\section{References}

Atav, S., \& Spencer G. A. (2002). Health risk behaviors among adolescents attending rural, suburban, and urban schools: A comparative study. Family and Community Health, 25, 53-64.

Bandura, A. (1986). Social foundations of thought and action: A social cognitive theory. Englewood Cliffs, NJ: Prentice-Hall.

Bauman, A., \& Phongsavan P. (1999). Epidemiology of substance use in adolescence: Prevalence, trends and policy implication. Drugs and Alcohol Dependence, 55, 187-207.

Eklund, J. M. (2006). Adolescents at risk of persistent and antisocial behavior and alcohol problems: The role of behavior, personality 
and biological factors. Health Equity Studies, 7.

Fatusi, A. O., \& Hindin M. J. (2010). Adolescents and youth in developing countries: Health and development issues in context. Journal of Adolescence, 33, 499-508.

Flisher, A. J., Parry, C. D. H., Evans, J., Muller, M., \& Lombard C. (2003). Substance use by adolescents in Cape Town: Prevalence and correlates. Journal of Adolescent Health, 1, 58-65.

Ghuman, S., Meyer-Weitz, A., \& Knight, S. (2012). Prevalence patterns and predictors of alcohol use and abuse among secondary school students in Southern kwaZulu-Natal, South Africa: demographic factors and the influence of parents and peers. South African Family Practice, 54, 132-138. [Online] Available: http://www.safp. (August 13, 2013).

Kalideen, N. (29 July 2011 p.2). 'Binge drinking rife at universities". In Mail and Guardian. Johannesburg.

McDonald, J. D. (2008). The advantages of Measuring Personality Constructs and disadvantages of Self-Reports, Informant reports and behavioural assessment. ENQUIRE, 1. [Online] Available: http://www. Nottingham.ac.uk. (August 21, 2013).

McMillan, J. H., \& Schumacher, S. (2010). Research in education: Evidence-based inquiry. (7th ed.). Boston: Pearson.

Madu, N.S., \& Matla M.P. (2003). Illicit drugs use, cigarette smoking and alcohol drinking behaviour among a sample of high school adolescents in the Pietersburg area of the Northern Province, South Africa. Journal of Adolescence, 26, 121-136.

Masten, A.S., Faden, V.B., Zucker, R.A., \& Spear, L.P. (2008). Underage Drinking: A Developmental Framework. Pediatrics, 121. [Online] Available: http://pediatrics.aappublications.org/content/121/supplement-4/S235.full. (August 13, 2013).

Morojele, N. (1997). Indigenous approaches to the treatment of substance abuse in South Africa. Pretoria:Medical Research Council.

Mwamwenda, T.S. (2004). Educational psychology: An African perspective. Johannesburg: Heinemann.

Nkonzo-Mthembu, L.L. (1994). An investigation of the opinions of black adolescents in the Esikhawini area of Kwa-Zulu in regard to the use and abuse of alcohol. Curationis, 17, 50-53.

Onya, H. Tessera, A., Myers, B., \& Flisher A.J. (2012). Adolescents alcohol use in rural South African high schools. African Journal of Psychiatry, 15, 352-357. [Online] Available: http://dx.doi.org/10.4314/ajpsy.vl5i5.44. (August 13, 2013).

Parry, C. D. H., Myers., B. Morojele., N. K. Flisher, A. J., Bhana, A., Donson, H., \& Pluddemann. A. (2004). Trends in alcohol and other drug use: findings from three sentinel sites in South Africa (1997-2001). Journal of Adolescence, 27, 429-440.

Peltzer, K., \& Cherian L. (2000). Substance use among urban and rural secondary school pupils in South Africa. Psychological Reports, $87,82-584$.

Peltzer, K., \& Phaswana N. (1999). Substance use among South African university learners: A qualitative and quantitative study. Urban Health and Development Bulletin, 2, 36-45.

Peltzer, K., Cherian, V. I., \& Cherian L. (1999). Substance use among urban secondary school pupils in the Northern Province, South Africa. Southern African Journal of Child and Adolescent Mental Health, 11, 49-55.

Peltzer, K., \& Ramlagan S. (2007). Cannabis use trends in South Africa. South African Journal of Psychiatry, 13, 126-131.

Pengpid, S., Peltzer, K., van der Heever, H., \& Skaal L. (2013). Screening and brief interventions for hazardous and harmful alcohol use among university students in South Africa: Results from a randomized controlled trial. International Journal of Environmental Research and Public Health 10, 2043-2057. [Online] Available: www.mdpi.com/journal/ijerph.

Petraitis, J., Flay B. R., \& Miller T. Q. (1995). Reviewing theories of substance use: Organising pieces in the puzzle. Psychological Bulletin, 117, 67-86.

Setlalentoa, B.M.P., Pisa, P.T., Thekiso G.N., Ryke E.H. \& Du Loots T. 2010. The social aspects of alcohol misuse/abuse in South Africa. South African Journal of Clinical Nutrition, 23, 11-15.

Slavin, R. E. (2012). Educational psychology: Theory and practice, Cape Town: Pearson.

Smart, R. G. (1980). A methodology for student drug-use survey. Geneva: WHO (Publication N 50).

Spruijt, E., \& Jurijen G.M. (1999). Life experiences, identity and adolescents' soft drugs use in the Netherlands. Journal of Alcohol and Drugs Education, 45, 47-59.

Visser, M., \& Moleko A. G. (1999). High school risk behaviour of primary learners. Urban Health and Development Bulletin, $2,70-83$.

Young, C., \& de Klerk V. (2008). Patterns of alcohol usage on a South African university campus: the findings of two annual drinking surveys. African Journal of drug Alcohol Studies, 7, 101-112.

Young, C., \& Mayson T. (2010). The alcohol use disorders identification scale (AUDIT) normative scores for a multiracial sample of Rhodes University residence students. Journal of Child and Adolescent Mental Health, 22, 15-23.

Zhang, Y., Lu., C. Zhang, J., Song H., Li, J., \& Kang L. (2013). Gender differences in abusers of amphetamine-type stimulants and ketamine in southwestern China. Addictive Behaviours, 38, 1424-1430.

Zimmerman, B. J. \& Schunk, D. H. (Eds.), (2003). Educational psychology: A century of contributions. Mahwah, NJ: Erlbaum. 